\title{
Sulfadiazine resistance in Toxoplasma gondii: no involvement of overexpression or polymorphisms in genes of therapeutic targets and $A B C$ transporters
}

\author{
Christelle Doliwa ${ }^{1, a}$, Sandie Escotte-Binet ${ }^{1, a}$, Dominique Aubert ${ }^{1,2}$, Virginie Sauvage ${ }^{1}$, \\ Frédéric Velard $^{3,4}$, Aline Schmid ${ }^{1}$, and Isabelle Villena ${ }^{1,2, *}$ \\ Laboratoire de Parasitologie-Mycologie, EA 3800, SFR CAP-Santé FED 4231, UFR Médecine, Université de Reims \\ Champagne-Ardenne, 51 rue Cognacq-Jay, 51095 Reims Cedex, France \\ 2 CRB Toxoplasma et CNR de la Toxoplasmose, Hôpital Maison Blanche, 45 rue Cognacq- Jay, 51092 Reims Cedex, France \\ 3 Plateforme d'Imagerie Cellulaire et Tissulaire, 51 rue Cognacq-Jay, 51096 Reims Cedex, France \\ 4 EA 4691 BIOS : Biomatériaux et inflammation en site osseux, SFR CAP-Santé FED 4231, Université de Reims Champagne-Ardenne, \\ 51 rue Cognacq-Jay, 51095 Reims Cedex, France
}

Received 28 January 2013, Accepted 14 May 2013, Published online 27 May 2013

\begin{abstract}
Several treatment failures have been reported for the treatment of toxoplasmic encephalitis, chorioretinitis, and congenital toxoplasmosis. Recently we found three Toxoplasma gondii strains naturally resistant to sulfadiazine and we developed in vitro two sulfadiazine resistant strains, RH- ${ }^{\mathrm{SDZ}}$ and $\mathrm{ME}-49-\mathrm{R}^{\mathrm{SDZ}}$, by gradual pressure. In Plasmodium, common mechanisms of drug resistance involve, among others, mutations and/or amplification within genes encoding the therapeutic targets $d h p s$ and $d h f r$ and/or the $\mathrm{ABC}$ transporter genes family. To identify genotypic and/or phenotypic markers of resistance in $T$. gondii, we sequenced and analyzed the expression levels of therapeutic targets dhps and $d h f r$, three $\mathrm{ABC}$ genes, two Pgp, $\operatorname{Tg} A B C . B 1$ and $T g A B C . B 2$, and one MRP, $T g A B C . C 1$, on sensitive strains compared to sulfadiazine resistant strains. Neither polymorphism nor overexpression was identified. Contrary to Plasmodium, in which mutations and/or overexpression within gene targets and ABC transporters are involved in antimalarial resistance, T. gondii sulfadiazine resistance is not related to these toxoplasmic genes studied.
\end{abstract}

Key words: Toxoplasma gondii, sulfadiazine resistance, dhps, dhfr, ABC transporters.

Résumé - Résistance à la sulfadiazine chez Toxoplasma gondii : pas de participation de surexpression ni de polymorphismes dans les gènes des cibles thérapeutiques et des $\mathrm{ABC}$ transporteurs. De nombreux échecs thérapeutiques ont été rapportés dans le traitement de la toxoplasmose cérébrale, des choriorétinites et de la toxoplasmose congénitale. Récemment, nous avons identifié trois souches de Toxoplasma gondii naturellement résistantes à la sulfadiazine et nous avons développé in vitro, par pression médicamenteuse croissante, deux souches résistantes à la sulfadiazine, $\mathrm{RH}-\mathrm{R}^{\mathrm{SDZ}}$ et ME-49-R $\mathrm{R}^{\mathrm{SDZ}}$. Chez Plasmodium, les mécanismes de résistance impliquent, entre autres, la mutation et/ou l'amplification de gènes codant pour les cibles thérapeutiques, dhps et $d h f r$, et/ou les gènes de la famille des $\mathrm{ABC}$ transporteurs. Afin d'identifier des marqueurs génotypiques et/ou phénotypiques de résistance de $T$. gondii, nous avons séquencé et analysé les niveaux d'expression des gènes cibles, dhps, dhfr, et de trois gènes de transporteurs ABC, deux Pgp, $\operatorname{Tg} A B C . B 1$ et $\operatorname{Tg} A B C . B 2$, et une MRP, $\operatorname{Tg} A B C . C 1$, par comparaison des souches sensibles et résistantes à la sulfadiazine. Aucun polymorphisme ni surexpression de gènes n'ont été identifiés. Contrairement à Plasmodium, dont les mutations et/ou surexpressions des gènes cibles et $\mathrm{ABC}$ transporteurs sont impliquées dans la résistance aux antipaludiques, les mécanismes de résistance à la sulfadiazine chez $T$. gondii ne sont pas liés à ces gènes toxoplasmiques étudiés.

\footnotetext{
${ }^{a}$ These authors contribute equally to this work.

*Corresponding author: ivillena@chu-reims.fr
} 


\section{Introduction}

The apicomplexan Toxoplasma gondii, an obligate intracellular parasite, can infect humans and a wide range of vertebrates leading to toxoplasmosis. This generally benign affection can cause severe life-threatening disease, particularly in immunocompromised patients and in congenitally affected children [17]. The population structure of $T$. gondii consists of three main clonal lineages (Type I (including RH, a highly virulent strain), Type II (including avirulent strains like ME-49 and PRU), and Type III (including avirulent strains like NED)) correlated with virulence expression in mice [5]. Recently, a study revealed a biphasic pattern consisting of regions in the Northern Hemisphere where a few highly clonal and abundant lineages predominate; elsewhere, and especially in portions of South America, they are characterized by a diverse assemblage of less common genotypes that show greater evidence of recombination [14].

Treatment of toxoplasmosis usually uses a combination of a sulfamide with pyrimethamine, which has a remarkable synergistic activity against the replicating form of $T$. gondii, through the sequential inhibition of parasite dihydropteroate synthase (DHPS) and dihydrofolate reductase (DHFR). These two major enzymes are responsible for the synthesis of the folate compounds that are essential for parasite survival and replication. However, several treatment failures have been reported for treatment of toxoplasmic encephalitis, chorioretinitis and congenital toxoplasmosis [16]. Whether these failures are related to host factors (drug intolerance, malabsorption, poor compliance) and/or to the development of drug-resistant parasites or a lower susceptibility of the parasite strain is debated. Recently, in vitro susceptibilities of $17 \mathrm{~T}$. gondii strains belonging to various genotypes were evaluated with the widely used anti-toxoplasmic drugs including sulfadiazine, pyrimethamine, and atovaquone [7]. Some variability in the susceptibilities of $T$. gondii strains to pyrimethamine and atovaquone were found but with no clear evidence of drug resistance. On the other hand, higher variability was found for sulfadiazine with in vitro resistance for three strains, $\operatorname{TgH} 32006$, previously described as RMS-1995-ABE, TgH 32045, previously described as RMS-2001-MAU, and TgA 103001, previously described as B1, not correlated to strain genotypes or growth kinetics [7]. Moreover, in order to understand sulfadiazine resistance mechanisms in $T$. gondii, we developed in vitro two sulfadiazine-resistant strains, named $\mathrm{RH}-\mathrm{R}^{\mathrm{SDZ}}$ and $\mathrm{ME}-49-\mathrm{R}^{\mathrm{SDZ}}$, by drug pressure [3].

The molecular basis of resistance to antifolates is well documented in P. falciparum and consists of point mutations in genes encoding for both dhps and $d h f r$. Resistance to pyrimethamine has been shown to result from a mutation in the DHFR enzyme, changing Ser108 to Asn108, and subsequent mutations (N51I, C59R, I164L, and A16V) can greatly increase the level of resistance to this drug. Resistance to sulfonamides and sulfones has been demonstrated to result from mutations within DHPS, such as amino acid changes at five positions (S436A/F, A437G, K540E, A581G, A613/T) [2]. In T. gondii, Aspinall et al. (2002) [2] demonstrated by direct sequencing of PCR products the presence of six mutations at positions 407, $474,560,580,597$, and 627 within DHPS. Only the mutation at position 407, which is equivalent to the 437 position in Plasmodium, was reported as being associated with sulfonamides resistance. This mutation was also retrieved in the laboratoryinduced sulfamethoxazole-resistant strain $\left(\mathrm{R}-\mathrm{Sul}^{\mathrm{R}}-5\right)$ [8].

We previously demonstrated that accumulation and efflux of xenobiotics from parasites were modulated by P-glycoprotein (Pgp) and Multidrug resistance-associated protein (MRP) inhibitors, indicating their presence and activity in $T$. gondii [10]. Pgp and MRP proteins belong to the ATP-binding cassette (ABC) superfamily of transporters. So far, we have identified in the $T$. gondii genome 24 genes related to the $\mathrm{ABC}$ whose expression was detected both in tachyzoite and bradyzoite infectious stages for the three genotypes (I, II, and III) [12]. Among these 24 genes, two encode for whole Pgps: $T g A B C . B 1$ (1345 amino acids) [10] and $T g A B C . B 2$ (1407 amino acids) and one encodes for a MRP, TgABC.C1 (1883 amino acids). Pgp and MRP are widely reported to export xenobiotics and cause drug resistance in tumor cells [1] and protozoan parasites [11] and lead to drug resistance by increasing drug efflux from the cell, thus lowering the effective intracellular drug concentration. The increased activities of the $\mathrm{ABC}$ transporters could be due to an increased amount of proteins due to gene amplification or overexpression associated or not associated with point mutations in the genomic sequence. In P. falciparum, antimalarial resistance involves mutations and/or amplification of one Pgp and MRP genes, PfABCB1 (alias Pgh1 and PfMDRl) and $P f A B C C 1$ (alias $P f M R P$ ), respectively. Mutations in PfABCB1 are identified in clinical isolates from different geographical areas. Polymorphisms are observed at five positions - codons $86,184,1034,1042$, and 1246. PfABCB1 overexpression is the only mechanism suggested to date involved in mefloquine-resistant parasites [9]. Concerning PfABCC1, mutations at positions $191 \mathrm{His}$ and $437 \mathrm{Ser}$ are found to be linked $100 \%$ to decreased quinolone resistance in southeastern Iranian isolates [15].

In our present study, we sequenced and analyzed the expression levels of the therapeutic targets dhps and $d h f r$ and three ABC transporters, $T g A B C . B 1, T g A B C . B 2$ and $T g A B C . C 1$, in sulfadiazine-sensitive and resistant $T$. gondii strains to identify genotypic and/or phenotypic markers of resistance.

\section{Material and methods}

\section{Cell culture}

T. gondii tachyzoites were maintained on Vero cell monolayers (ATCC, CCL-81) at $37{ }^{\circ} \mathrm{C}$ in a $5 \% \mathrm{CO}_{2}$ humidified incubator. Cells and parasites were grown in complete medium: Iscove's Modified Dulbecco's Medium/Glutamax (IMDM; Invitrogen, France) supplemented with $2 \%(\mathrm{v} / \mathrm{v})$ fetal calf serum (Biowest, France) and antibiotics (100 IU/mL penicillin and $0.1 \mathrm{mg} / \mathrm{mL}$ streptomycin) (GIBCO) as previously described [3].

\section{Polymorphisms analysis}

Identification of polymorphic sites of dhps, dhfr, $T g A B C . B 1, T g A B C . B 2$, and $T g A B C . C 1$ genes was carried out 
by using PCR amplification and direct sequencing [13]. Strain polymorphisms were analyzed by alignment of the nucleotide sequences according to the ClustalW multiple sequence alignment program at the website of EMBL-EBI (http://www. ebi.ac.uk//clustalw/index.html).

\section{qRT-PCR analysis}

The protocol used was previously described [13]. PCR primers (Invitrogen ${ }^{\mathrm{TM}}$ Life Technologies, France) were designed using Primer express 2.0 (Applied Biosystems, USA) to specifically amplify sequences of $d h p s: 5^{\prime}$-TCA TTT CCG TTG ACA CCA TGA-3' (forward) and 5'-TCT CCG GTC TGG TCG TTC AC-3' (reverse), dhfr: 5'-CTG GAG GAA GAG TAC AAG GAT TCT GA-3' (forward) and $5^{\prime}$-AAG CAA CGC CCA GAG ACA-3' (reverse), TgABC.B1: 5'-GCG TGT GTT TGC ACT GAT TGA-3' (forward) and 5'-TTG CGT TGT CGC TGA ACT TC-3' (reverse), TgABC.B2 : 5'-CGA TCG TGC AGA TGC TTC AA-3' (forward) and 5'-GCT GTG CAC GCA GAT ACT GAA T-3' (reverse), TgABC.C1: 5'ACA CTC TCC CTT CAT TCA CAA G-3' (forward) and 5'-CAG AAG GTG AAT CAC TGG AAT GG-3' (reverse), and the toxoplasma $\beta$-tubulin: $5^{\prime}$-TCT TCC GCC CTG ACA ACT TC-3' (forward) and 5'-CCG CAC CCT CAG TGT AGT GA-3' (reverse). Results are representative of at least five independent experiments and presented as median \pm interquartile spaces (IQs). ${ }^{*} p<0.05$ represent significant difference between strains (Non-parametric exact Wilcoxon-MannWhitney test).

\section{Nucleotide sequence data}

Nucleotide sequence data reported in this paper are available in the GenBank ${ }^{\mathrm{TM}}$, EMBL, and DDJB databases under the accession numbers: EU213065, EF418617, FJ201251, EU213066, EF418618, EJ201252, EU213067, EF418619, FJ201253, GQ415579, GQ397454, FJ201257, FJ215662, GQ865628, GQ415585, GQ397458, FJ201258, GQ865630, GQ865629, GQ415580, GQ397459, FJ201255, FJ201256, FJ201254, GQ415574, GQ395774.

\section{Results and discussion}

To identify genotypic and/or phenotypic markers of resistance, we sequenced and analyzed the expression levels of the therapeutic targets $d h p s$ and $d h f r$ on sensitive strains representative of the three major genotypes (Type I (RH), Type II (ME-49 or PRU), and Type III (NED)), compared to the three naturally resistant strains described (TgA 103001 (Type I), TgH 32006 (Type II), and TgH 32045 (Type II variant)). For the polymorphisms analysis, the Type II strain ME-49 was considered as reference; genotype II strains were found in $95 \%$ of cases of toxoplasmosis in France. The complete sequence of the 6 exons of the dhps gene showed three identical mutations in the exons 2 (E474D), 4 (R560K), and 5 (A597E, two silent mutations) of the sensitive strain $\mathrm{RH}$ as well as in the resistant strain TgA 103001, one of the three naturally resistant strains to sulfadiazine (Table 1). This mutation was also found in one recombinant Type I/III strain (TgH 32005A, previously described as RMS-1994-LEF) and in one atypical strain isolated in French Guyana (TgH 18007A, previously described as GUY-2003-MEL), both of them tested as sensitive to sulfadiazine [7]. In the resistant strain $\mathrm{TgH} 32006$, one mutation converting Alanine to Valine at position 587 was found in exon 5 [7]. The significance of this new mutation on the dhps gene demonstrated in one of the three resistant strains remains to be determined. In addition, no mutation was found at position 407 in the three resistant strains analyzed. As previously described [7], one silent mutation in exon 3 (156L) of the $d h f r$ gene was found in the two Type I strains, the sensitive strain $\mathrm{RH}$ and the resistant strain TgA 103001. ABC transporters have been reported to be involved in drug resistance in protozoa [11]. We have sequenced and analyzed the expression levels of $T g A B C . B 1, \operatorname{Tg} A B C . B 2$, and $\operatorname{Tg} A B C . C 1$ on three sensitive and three naturally resistant strains. The sequencing of $T g A B C . B 1$ (35 exons), $T g A B C . B 2$ (33 exons) and $T g A B C . C 1$ (9 exons) coding regions on the three major genotypes - Type I (RH), Type II (PRU), and Type III (NED) - shows 26, 29, and 27 single nucleotide polymorphisms, respectively. $\operatorname{Tg} A B C . B 1$ shows silent mutations at 24 sites, discriminating the RH, PRU, and NED strains. Two mutations, in the exons 1 (A9T) and 35 (K1324Q), lead to changes in amino acids which helped distinguish between Type II and non-Type II $T$. gondii strains (Table 1). Several silent mutations were found in the $T g A B C . B 1$ gene according to different strain genotypes. Concerning $T g A B C . B 2,22$ silent mutations sites, of which seven single nucleotide polymorphisms that help distinguish between Type I and non-Type I T. gondii strains, were identified. TgH 32045 presented one mutation in exon 18 (L729M) found in the Type I strains. The $\operatorname{TgABC}$.C1 gene shows 17 silent mutations in the coding region, of which 10 mutation sites lead to changes in amino acids, discriminating the Type I and non-Type I strains (Table 1). $\mathrm{TgH} 32045$ presented one mutation in exon 9 (H1659Q) found in the Type I sulfadiazine-resistant strain (TgA 103001). This mutation was retrieved in all Type I strains subsequently studied (except RH), as well as on atypical strains from special geographical regions, like French Guyana and Brazil (data not shown). The low polymorphism percentage observed for the different genes studied is in concordance with the genetic variation level estimated to be less than $2 \%$ among the predominant clonal lineages [4]. The expression level of each therapeutic target was analyzed using standard semi-quantitative real-time RT-PCR for all the strains studied. After normalizing transcript levels of $d h p s$ and $d h f r$ to $\beta$-tubulin, no significant variation of $d h f r$ gene expression was observed between resistant and sensitive strains (Figure 1). However, we observed a significant decrease $(p<0.05)$ of dhps gene expression in the resistant strain $\mathrm{RH}-\mathrm{R}^{\mathrm{SDZ}}$ in comparison to the sensitive RH strain and in the two Type II resistant strains $\mathrm{TgH} 32006$ and ME-49- $\mathrm{R}^{\mathrm{SDZ}}$ in comparison to the sensitive ME-49 strain. These results were not consistent with overexpression of therapeutic targets found in Plasmodium. Hence, no polymorphism or overexpression of therapeutic targets is involved in $T$. gondii sulfadiazine resistance. The RNA expression levels from the two Pgp and the MRP demonstrate that gene expression seems correlated with the strain genotype, as observed with Type I strains, which present the highest level 
Table 1. Polymorphisms in the therapeutic targets DHPS and DHFR and the three ABC proteins, TgABC.B1, TgABC.B2, and TgABC.C1, for three sensitive and naturally resistant strains representative of the three major genotypes (I, II, and III) in T. gondii. Only the polymorphisms leading to amino acid changes are represented. (*) corresponds to silent mutations. GenBank accession numbers are indicated for each case.

\begin{tabular}{|c|c|c|c|c|c|c|c|}
\hline & Genotype & $\begin{array}{c}\text { Sulfadiazine } \\
\text { susceptibility }\end{array}$ & $\operatorname{TgABC.B1}$ & $\operatorname{TgABC.B2}$ & $\operatorname{TgABC.C1}$ & dhps & $d h f r$ \\
\hline $\mathrm{RH}$ & I & Sensitive & $\begin{array}{c}*(20) \\
\text { T9A,K1285Q } \\
\text { EU213065.1 }\end{array}$ & $\begin{array}{c}*(22) \\
\text { S2N, S267N, } \\
\text { G368D, I509T, } \\
\text { L729M, M848L, L883I } \\
\text { EF418617.1 }\end{array}$ & $\begin{array}{c}*(19) \\
\text { K7E, D491E, T665S } \\
\text { G672E, H954P, G968A } \\
\text { E1125A, S1718R } \\
\text { V1722A, P1785S } \\
\text { FJ201251.1 }\end{array}$ & $\begin{array}{c}*(2) \\
\text { E474K, R560K } \\
\text { A597E }\end{array}$ & $*(1)$ \\
\hline PRU & II & Sensitive & $\begin{array}{c}0 \\
\text { EU213066.1 }\end{array}$ & $\begin{array}{c}0 \\
\text { EF418618.1 }\end{array}$ & $\begin{array}{c}0 \\
\text { FJ201252.1 }\end{array}$ & $\begin{array}{c}0 \\
\text { GQ415579.1 }\end{array}$ & $\begin{array}{c}0 \\
\text { GQ397454.1 }\end{array}$ \\
\hline NED & III & Sensitive & $\begin{array}{c}*(13) \\
\text { T9A,K1285Q } \\
\text { EU213067.1 }\end{array}$ & $\begin{array}{c}0 \\
\text { EF418619.1 }\end{array}$ & $\begin{array}{c}0 \\
\text { FJ201253.1 }\end{array}$ & $\begin{array}{c}0 \\
\text { GQ415579.1 }\end{array}$ & $\begin{array}{c}0 \\
\text { GQ397454.1 }\end{array}$ \\
\hline TgA 103001 & I & Resistant & $\begin{array}{c}*(19) \\
\text { T9A, K1285Q } \\
\text { FJ201255.1 }\end{array}$ & $\begin{array}{c}*(23) \\
\text { S2N, S267N, } \\
\text { G368D, I509T, } \\
\text { G816E, M848L, L883I } \\
\text { FJ201256.1 }\end{array}$ & $\begin{array}{c}*(23) \\
\text { K7E, D491E, } \\
\text { G782A } \\
\text { H954P, G968A } \\
\text { E1125A, G1440A, H1659Q, } \\
\text { S1718R, V1722A, P1785S } \\
\text { FJ201254.1 }\end{array}$ & $\begin{array}{c}*(2) \\
\text { E474K, } \\
\text { R560K, A597E } \\
\text { GQ415574.1 }\end{array}$ & $\begin{array}{c}*(1) \\
\text { GQ415574.1 }\end{array}$ \\
\hline TgH 32006 & II & Resistant & $\begin{array}{c}0 \\
\text { FJ201257.1 }\end{array}$ & $\begin{array}{c}0 \\
\text { FJ215662.1 }\end{array}$ & $\begin{array}{c}0 \\
\text { GQ865628.1 }\end{array}$ & $\begin{array}{c}\text { A587V } \\
\text { GQ865628.1 }\end{array}$ & $\begin{array}{c}0 \\
\text { GQ397458.1 }\end{array}$ \\
\hline TgH 32045 & II Variant & Resistant & $\begin{array}{c}*(1) \\
\text { FJ201258.1 }\end{array}$ & $\begin{array}{c}*(1) \\
\text { L729M } \\
\text { GQ865630.1 }\end{array}$ & K642E, H1659Q & GQ415580.1 & GQ397459.1 \\
\hline
\end{tabular}



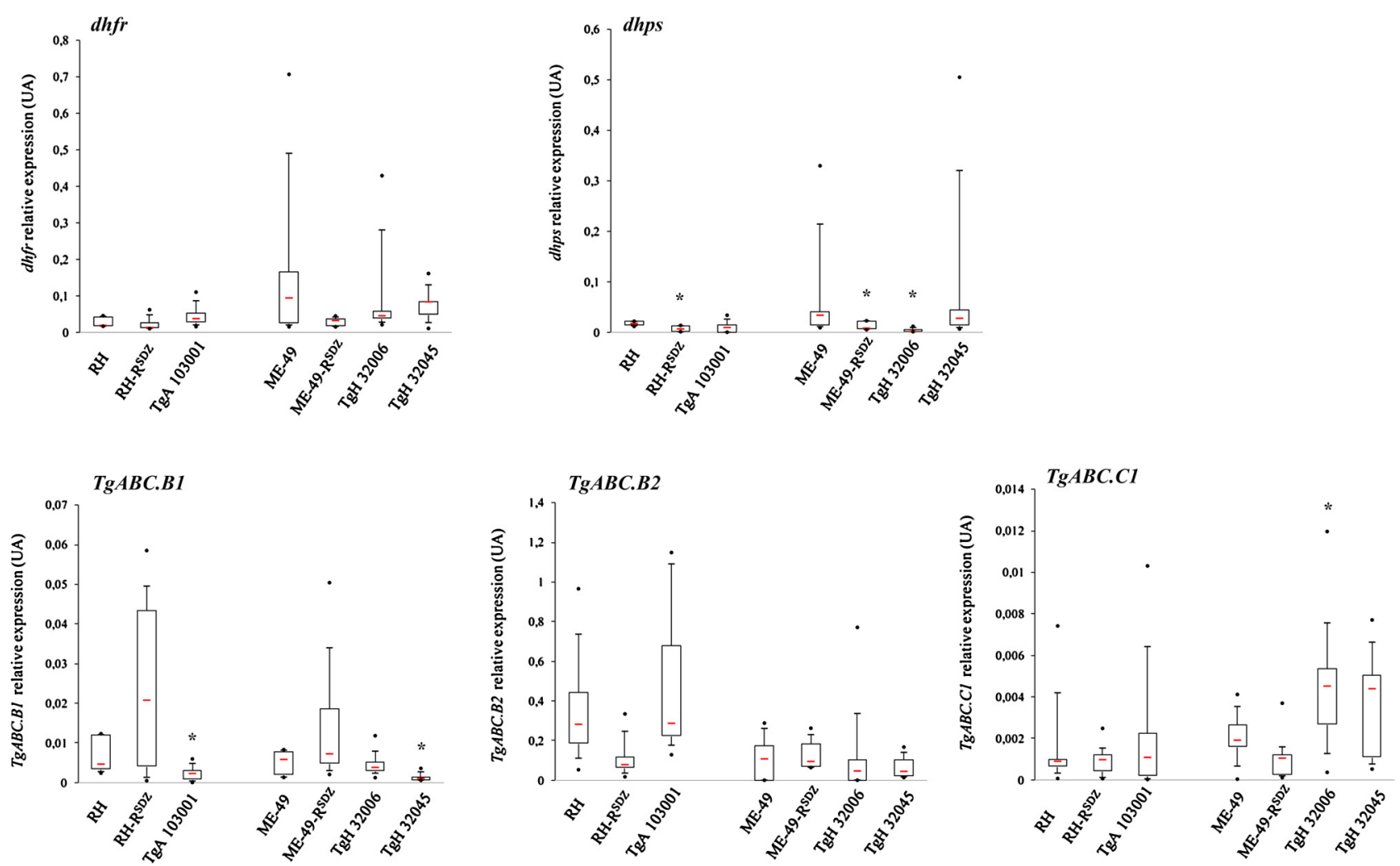

Figure 1. Relative expression of $d h p s$, dhfr, $\operatorname{TgABC} . B 1, \operatorname{Tg} A B C . B 2$, and $\operatorname{Tg} A B C$.C1 genes in two sensitive strains H (I) ME-49 (II), and the induced-resistant strains, RH-R ${ }^{\mathrm{SDZ}}$ and ME- $49-\mathrm{R}^{\mathrm{SDZ}}$, and naturally resistant strains TgA 103001, TgH 32006, and TgH 32045 by qRT-PCR analysis. Red bars represent median value. Black points represent maximum and minimum values. Black bars represent first and tenth decile and limits of white rectangle represents first and third quartile.

of expression for the $\operatorname{Tg} A B C . B 2$ gene. The virulent strains are characterized by a high growth rate compared to avirulent strains, which could involve a greater metabolism and therefore an efficient detoxification mechanism. This could explain the higher expression of $T g A B C . B 2$ in the sensitive $\mathrm{RH}$ strain and the resistant $\operatorname{TgA} 103001$ strain (Figure 1). As gene overexpression, including some $\mathrm{ABC}$ genes (ABC.G5, ABC1, $A B C 2$ ), especially for RH versus other Type I isolates, has been previously described [6], we analyzed the $\operatorname{Tg} A B C$. $B 2$ gene on ENT strain (Type I). No variation of $T g A B C . B 2$ gene expression was observed; RH and ENT strains have the same $T g A B C$. B2 gene expression variability (data not shown). Moreover, we observed a statistical decrease $(p<0.05)$ in $\operatorname{Tg} A B C . B 1$ gene expression for the resistant strains $\operatorname{TgA} 103001$ (Type I) and TgH 32045 (Type II variant) compared to the sensitive strains RH (Type I) and ME-49 (Type II). Interestingly, we observed a significant overexpression of $\operatorname{TgABC.C1}(p<0.05)$ in the resistant strain $\mathrm{TgH} 32006$ compared to the sensitive strain ME-49, but no significant variation of this gene was observed in the other two naturally resistant strains, TgA 103001 and $\mathrm{TgH}$ 32045. Moreover, no significant overexpression of $T g A B C . B 1$ and $T g A B C . C 1$ was observed in the two resistantinduced strains, $\mathrm{RH}-\mathrm{R}^{\mathrm{SDZ}}$ and ME-49- $\mathrm{R}^{\mathrm{SDZ}}$ (Figure 1).

In conclusion, we demonstrated that, in the case of $T$. gondii, sulfadiazine resistance does not involve polymorphisms and/or overexpression in dhfr, dhps, $T g A B C . B 1$, and $T g A B C . B 2$ genes contrary to $P$. falciparum. These results imply that resistant mechanisms in $T$. gondii are different. Interestingly, an overexpression of $T g A B C$.C1 was observed in the Type II resistant strain $\mathrm{TgH} 32006$, further studies are needed to clarify its involvement in resistance mechanisms. Studies are underway to investigate the drug resistance mechanisms in $T$. gondii using a microarray approach by comparison between sensitive and sulfadiazine-resistant strains. The identification of genes associated with sulfadiazine resistance will allow us to understand the resistance mechanisms implicated.

Acknowledgements. This research was funded by a grant from Region Champagne-Ardenne and Roche Laboratory, which was awarded to C. Doliwa for completion of a doctorate degree. This work was supported by the "Centre de Ressources Biologiques (CRB) Toxoplasma" and the "Centre National de Référence (CNR) de la Toxoplasmose". We would like to acknowledge R. Geers, N.Ortis, E. Dupuis, and E. Pisano for kindly providing T. gondii parasites. We thank Tiffany Gnemmi for checking English.

\section{References}

1. Ambudkar SV, Dey S, Hrycyna CA, Ramachandra M, Pastan I, Gottesman MM. 1999. Biochemical, cellular, and pharmacological aspects of the multidrug transporter. Annual Review of Pharmacology and Toxicology, 39, 361-398.

2. Aspinall TV, Joynson DH, Guy E, Hyde JE, Sims PF. 2002. The molecular basis of sulfonamide resistance in Toxoplasma gondii 
and implications for the clinical management of toxoplasmosis. Journal of Infectious Diseases, 185, 1637-1643.

3. Doliwa C, Escotte-Binet S, Aubert D, Velard F, Schmid A, Geers R, Villena I. 2013. Induction of sulfadiazine resistance in vitro in Toxoplasma gondii. Experimental Parasitology, 133, 131-136.

4. Grigg ME, Bonnefoy S, Hehl AB, Suzuki Y, Boothroyd JC. 2001. Success and virulence in Toxoplasma as the result of sexual recombination between two distinct ancestries. Science, 294, 161-165.

5. Howe DK, Sibley LD. 1995. Toxoplasma gondii comprises three clonal lineages: correlation of parasite genotype with human disease. Journal of Infectious Diseases, 172, 1561-1566.

6. Khan A, Behnke MS, Dunay IR, White MW, Sibley LD. 2009. Phenotypic and gene expression changes among clonal Type I strains of Toxoplasma gondii. Eukaryotic Cell, 8, 1828-1836.

7. Meneceur P, Bouldouyre MA, Aubert D, Villena I, Menotti J, Sauvage V, Garin JF, Derouin F. 2008. Toxoplasma gondii: in vitro susceptibility of various genotypic strains to pyrimethamine, sulfadiazine and atovaquone. Antimicrobial Agents and Chemotherapy, 52, 1269-1277.

8. Pfefferkorn ER, Borotz SE, Nothnagel RF. 1992. Toxoplasma gondii: characterization of a mutant resistant to sulfonamides. Experimental Parasitology, 74, 261-270.

9. Price RN, Uhlemann AC, Brockman A, McGready R, Ashley E, Phaipun L, Patel R, Laing K, Looareesuwan S, White NJ, Nosten F, Krishna S. 2004. Mefloquine resistance in Plasmodium falciparum and increased pfmdr1 gene copy number. Lancet, 364, 438-447.

10. Sauvage V, Aubert D, Bonhomme A, Pinon JM, Millot JM. 2004. P-glycoprotein inhibitors modulate accumulation and efflux of xenobiotics in extra and intracellular Toxoplasma gondii. Molecular and Biochemical Parasitology, 134, 89-95.
11. Sauvage V, Aubert D, Escotte-Binet S, Villena I. 2009. The role of ATP-binding cassette (ABC) proteins in protozoan parasites. Review. Molecular and Biochemical Parasitology, 167, 81-94.

12. Sauvage V, Millot JM, Aubert D, Visneux V, Marle-Plistat M, Pinon JM, Villena I. 2006. Identification and expression analysis of ABC protein-encoding genes family in Toxoplasma gondii. Molecular and Biochemical Parasitology, 147, 177-192.

13. Schmid A, Sauvage V, Escotte-Binet S, Aubert D, Terryn C, Garnotel R, Villena I. 2009. Molecular characterization and expression analysis of a P-glycoprotein homologue in Toxoplasma gondii. Molecular and Biochemical Parasitology, 163, $54-60$.

14. Su C, Khan A, Zhou P, Majumdar D, Ajzenberg D, Dardé ML, Zhu XQ, Ajioka JW, Rosenthal BM, Dubey JP, Sibley LD. 2012. Globally diverse Toxoplasma gondii isolates comprise six major clades originating from a small number of distinct ancestral lineages. Proceedings of the National Academy of Sciences of the United State of America, 109, 5844-5849.

15. Ursing J, Zakeri S, Gil JP, Björkman A. 2006. Quinoline resistance associated polymorphisms in the pfcrt, pfmdr1 and pfmrp genes of Plasmodium falciparum in Iran. Acta Tropica, 97, 352-356.

16. Villena I, Aubert D, Leroux B, Dupouy D, Talmud M, Chemla C, Trenque T, Schmit G, Quereux C, Guenounou M, Pluot M, Bonhomme A, Pinon JM. 1998. Pyrimethamine-sulfadoxine treatment of congenital toxoplasmosis: follow-up of 78 cases between 1980 and 1997. Reims Toxoplasmosis Group. Scandinavian Journal of Infectious Diseases, 30, 295-300.

17. Weiss LM, Dubey JP. 2009. Toxoplasmosis: a history of clinical observations. International Journal for Parasitology, 39, 895901.

Cite this article as: Doliwa C, Escotte-Binet S, Aubert D, Sauvage V, Velard F, Schmid A \& Villena I: Sulfadiazine resistance in Toxoplasma gondii: no involvement of overexpression or polymorphisms in genes of therapeutic targets and ABC transporters. Parasite, 2013, 20, 19.

Reviews, articles and short notes may be submitted. Fields include, but are not limited to: general, medical and veterinary parasitology; morphology, including ultrastructure; parasite systematics, including entomology, acarology, helminthology and protistology, and molecular analyses; molecular biology and biochemistry; immunology of parasitic diseases; host-parasite relationships; ecology and life history of parasites; epidemiology; therapeutics; new diagnostic tools.

All papers in Parasite are published in English. Manuscripts should have a broad interest and must not have been published or submitted elsewhere. No limit is imposed on the length of manuscripts.

Parasite (open-access) continues Parasite (print and online editions, 1994-2012) and Annales de Parasitologie Humaine et Comparée (1923-1993) and is the official journal of the Société Française de Parasitologie. 